medRxiv preprint doi: https://doi.org/10.1101/2020.04.20.20072462; this version posted April 24, 2020. The copyright holder for this preprint

(which was not certified by peer review) is the author/funder, who has granted medRxiv a license to display the preprint in perpetuity.

All rights reserved. No reuse allowed without permission.

\title{
ESTIMATING $\mathbf{R}_{0}$ OF SARS-COV-2 IN HEALTHCARE SETTINGS
}

\section{Laura TEMIME}

MESURS laboratory, Conservatoire national des arts et métiers, Paris, France; PACRI Unit, Institut Pasteur, Conservatoire national des arts et métiers, Paris, France.

Marie-Paule GUSTIN

Institute of Pharmaceutic and Biological Sciences, University Claude Bernard Lyon 1, Villeurbanne, France; Emerging Pathogens Laboratory-Fondation Mérieux, International Center for Infectiology Research (CIRI), Inserm U1111, CNRS UMR5308, ENS de Lyon, Lyon, France.

\section{Audrey DUVAL}

Université Paris-Saclay, UVSQ, Univ. Paris-Sud, Inserm, CESP, Anti-infective evasion and pharmacoepidemiology team, Montigny-Le-Bretonneux, France; Institut Pasteur, Epidemiology and Modelling of Antibiotic Evasion unit, Paris, France.

Niccolò BUETTI

INSERM IAME, U1137, Team DesCID, Paris, France.

\section{Pascal CRÉPEY}

UPRES-EA 7449 REPERES « Recherche en Pharmaco-Epidémiologie et Recours aux Soins 》 - EHESP Université de Rennes, Rennes, France.

\section{Didier GUILLEMOT}

Université Paris-Saclay, UVSQ, Univ. Paris-Sud, Inserm, CESP, Anti-infective evasion and pharmacoepidemiology team, Montigny-Le-Bretonneux, France; Institut Pasteur, Epidemiology and Modelling of Antibiotic Evasion unit, Paris, France; AP-HP Paris Saclay, Public Health, Medical Information, Clinical research, Le Kremlin-Bicêtre, France.

Rodolphe THIÉBAUT

INSERM U1219 Bordeaux Population Health, Université de Bordeaux, Bordeaux, France; INRIA SISTM team, Talence, France; Vaccine Research Institute, Créteil, France.

\section{Philippe VANHEMS}

Emerging Pathogens Laboratory-Fondation Mérieux, International Center for Infectiology Research (CIRI), Inserm U1111, CNRS UMR5308, ENS de Lyon, Lyon, France; Service d'Hygiène, Epidémiologie et Prévention, Hospices Civils de Lyon, F-69437, Lyon, France ; Inserm, F-CRIN, Réseau Innovative Clinical Research in Vaccinology (I-REIVAC), Paris, France.

Jean-Ralph ZAHAR

IAME, UMR 1137, Université Paris 13, Sorbonne Paris Cité, France; Service de Microbiologie Clinique et Unité de Contrôle et de Prévention du Risque Infectieux, Groupe Hospitalier Paris Seine SaintDenis, AP-HP, Bobigny, France.

David R.M. SMITH Université Paris-Saclay, UVSQ, Univ. Paris-Sud, Inserm, CESP, Anti-infective evasion and pharmacoepidemiology team, Montigny-Le-Bretonneux, France; Institut Pasteur, Epidemiology and Modelling of Antibiotic Evasion unit, Paris, France; MESuRS laboratory, Conservatoire national des arts et métiers, Paris, France.

Lulla OPATOWSKI 
Université Paris-Saclay, UVSQ, Univ. Paris-Sud, Inserm, CESP, Anti-infective evasion and pharmacoepidemiology team, Montigny-Le-Bretonneux, France; Institut Pasteur, Epidemiology and Modelling of Antibiotic Evasion unit, Paris, France.

On behalf of the "Modelling COVID-19 in hospitals" REACTing AVIESAN working group: Niccolò Buetti, Christian Brun-Buisson, Sylvie Burban, Simon Cauchemez, Guillaume Chelius, Anthony Cousien, Pascal Crepey, Vittoria Colizza, Christel Daniel, Aurélien Dinh, Pierre Frange, Eric Fleury, Antoine Fraboulet, Didier Guillemot, Marie-Paule Gustin, Bich-Tram Huynh, Lidia Kardas-Sloma, Elsa Kermorvant, Jean Christophe Lucet, Lulla Opatowski, Chiara Poletto, Laura Temime, Rodolphe Thiebaut, Sylvie van der Werf, Philippe Vanhems, Linda Wittkop, Jean-Ralph Zahar.

Keywords: COVID-19; basic reproduction number; modelling; hospital; nosocomial; transmission

Running title: $R_{0}$ of SARS-COV-2 in healthcare settings

Corresponding author:

Laura Temime

MESuRS laboratory

Conservatoire national des Arts et Métiers

292 rue Saint-Martin - 75141 Paris Cedex 03

France

Email: laura.temime@lecnam.net 
medRxiv preprint doi: https://doi.org/10.1101/2020.04.20.20072462; this version posted April 24, 2020. The copyright holder for this preprint (which was not certified by peer review) is the author/funder, who has granted medRxiv a license to display the preprint in perpetuity. All rights reserved. No reuse allowed without permission.

\begin{abstract}
To date, no specific estimate of $R_{0}$ for SARS-CoV-2 is available for healthcare settings. Using interindividual contact data, we highlight that $\mathrm{R}_{0}$ estimates from the community cannot translate directly to healthcare settings, with pre-pandemic $R_{0}$ values ranging 1.3-7.7 in three illustrative healthcare institutions. This has implications for nosocomial Covid-19 control.
\end{abstract}


medRxiv preprint doi: https://doi.org/10.1101/2020.04.20.20072462; this version posted April 24, 2020. The copyright holder for this preprint (which was not certified by peer review) is the author/funder, who has granted medRxiv a license to display the preprint in perpetuity. All rights reserved. No reuse allowed without permission.

In the context of the current Covid-19 pandemic, the basic reproduction number $\mathrm{R}_{0}$ has been recognized as a key parameter to characterize epidemic risk and predict spread of SARS-CoV-2, the causative virus of Covid-19 infection [1]. Ro describes the average number of secondary cases generated by an initial index case in an entirely susceptible population. $R_{0}$ is determined not only by the inherent infectiousness of a pathogen, but also environmental conditions, host contact behaviours and other factors that influence transmission. Understanding the evolution of the effective reproduction number $R_{t}$, which describes $R_{0}$ as it varies over time, is also essential for epidemiological forecasting and to assess the impact of control strategies [2, 3].

Over recent months, numerous estimates of $\mathrm{R}_{0}$ for SARS-CoV- 2 have been computed through analysis of reported infections from countries all over the world [2, 4-6], as well as in specific subpopulations, such as individuals aboard the Diamond Princess cruise ship [7]. Published estimates mostly range from 2-4.

However, to date, no estimates of $R_{0}$ specific to healthcare settings have been published.

Healthcare institutions are confronted with several urgent and overlapping challenges linked to Covid-19. Acute care facilities face unprecedented demand for beds and resources to accommodate Covid-19 patients, particularly in intensive care units in high-prevalence regions. Introduction of SARS-CoV-2 to healthcare settings can further result in nosocomial outbreaks, with superspreading events already reported in some hospitals [8], as was also observed for SARS-CoV and MERS-CoV. In addition to risks for patients, whose underlying conditions put them at greater risk of severe infection, there is also an important risk of infection among healthcare workers [8].

Contacts between individuals are fundamental to the spread of respiratory pathogens like SARS-CoV2, and contact patterns in healthcare settings are highly context-specific. Contacts between patients and healthcare workers tend to be simultaneously more frequent, longer and more at-risk than contacts occurring in the community. This could translate to higher $R_{0}$ values, as underlined in earlier 
work on other coronaviruses, in which $\mathrm{R}_{0}$ was estimated to be much higher in hospitals than in the community [9].

Here, using detailed individual-level contact pattern data from both the community and three healthcare institutions in France, we explore how the reproduction number estimated in the community translates to these institutions, and discuss potential consequences for public health.

\section{METHODS}

Under simplifying assumptions, $\mathrm{R}_{0}$ can be estimated as follows:

$$
\mathrm{R}_{0}=p \times d_{C t c} \times n_{C t c} \times d_{I n f}
$$

where $p$ is the probability of transmission per minute spent in contact, $d_{C t c}$ is the average contact duration (in minutes), $n_{C t c}$ is the average number of contacts per person per day, and $d_{\operatorname{lnf}}$ is the average duration of infectivity (in days): approximately 10 days for Covid-19 [10].

Assuming that $p$ and $d_{\ln f}$ are the same for individuals in the community and in healthcare settings, we can translate the previous expression into setting-specific $R_{0}$ values computed as:

- In the community: $\mathrm{R}_{0}^{C}=p \times d_{c t c}^{C} \times n_{C t c}^{C} \times d_{\text {Inf }}$

- In the healthcare settings: $\mathrm{R}_{0}^{\mathrm{H}}=p \times d_{c t c}^{H} \times n_{c t c}^{H} \times d_{\text {Inf }}$

where superscripts $C$ and $H$ denote values for community and healthcare settings, respectively.

The healthcare setting-specific reproduction number may then be estimated from the communityspecific reproduction number and the contact pattern characteristics in both settings, as:

$$
\mathrm{R}_{0}^{\mathrm{H}}=\mathrm{R}_{0}^{\mathrm{C}} \times \frac{d_{c t c}^{H} \times n_{c t c}^{H}}{d_{c t c}^{C} \times n_{c t c}^{C}}
$$

\section{NUMERICAL APPLICATION IN THE FRENCH CONTEXT}

Based on detailed inter-individual contact data from France [11], in the community the median number of inter-individual contacts per person is $n_{C t c}^{C}=8$ contacts/day and the median duration of 
these contacts ranges from 15 minutes to 1 hour. For simplicity, in the following we use $d_{c t c}^{C}=30$ minutes.

The reproduction number for SARS-CoV-2 has been estimated in the French community at values ranging from $R_{0}^{C}=2$ to $4[2,12,13]$. In the following we use $R_{0}^{C}=3$.

These translate to an average transmission risk per minute spent in contact of:

$$
p=3 /(8 \times 30 \times 10)=0.00125=0.125 \%
$$

Table 1 provides estimates of the healthcare setting-specific reproduction number $\mathrm{R}_{0}^{\mathrm{H}}$, depending on the average number of daily contacts with in the healthcare setting $n_{C t c}^{H}$, and the actual value of $\mathrm{R}_{0}^{\mathrm{C}}$. The mean duration of daily contacts within the healthcare setting $d_{C t c}^{H}$ is assumed to range from 10 to 40 minutes.

\section{THREE ILLUSTRATIVE EXAMPLES}

As an illustration, we used detailed contact data from three different healthcare settings in France during the pre-pandemic period to estimate $\mathrm{R}_{0}^{\mathrm{H}}$ in the absence of control measures specific to Covid19:

- For a 170-bed rehabilitation hospital [14], where $n_{c t c}^{H}=18$ contacts/day and $d_{C t c}^{H}=34 \mathrm{~min}$, the pre-pandemic $\mathrm{R}_{0}^{\mathrm{H}}$ is estimated as

$$
\mathrm{R}_{0}^{\mathrm{H}}=0.125 \% \times 34 \times 18 \times 10=7.65
$$

- For an acute-care geriatric unit [15], where the cumulative time spent in contact with others per individual per day was $n_{C t c}^{H} \times d_{C t c}^{H}=104 \mathrm{~min}$, the pre-pandemic $\mathrm{R}_{0}^{\mathrm{H}}$ is estimated as

$$
\mathrm{R}_{0}^{\mathrm{H}}=0.125 \% \times 104 \times 10=1.3
$$

- For a 100-bed nursing home [16], where the cumulative time spent in contact per individual and per day was $n_{C t c}^{H} \times d_{c t c}^{H}=615 \mathrm{~min}$, the pre-pandemic $\mathrm{R}_{0}^{\mathrm{H}}$ is estimated as 


$$
\mathrm{R}_{0}^{\mathrm{H}}=0.125 \% \times 615 \times 10=7.7
$$

\section{DISCUSSION}

Estimating $R_{0}$ has been an important focus of epidemiological work to understand the transmission dynamics and pandemic trajectory of SARS-CoV-2. We highlight here that reproduction numbers estimated in the community cannot be translated directly to healthcare settings, where interindividual contact patterns are specific to and variable between institutions.

Health care institutions are at high risk of SARS-CoV-2 importation, from admission of infected patients or from visitors or healthcare workers infected in the community. Our estimates of $\mathrm{R}_{0}^{\mathrm{H}}$ suggest that, depending on a healthcare facility's size and structure, the risk of nosocomial spread may be much higher or lower than in the general population, with values ranging from 0.4 to 13.3 (Table 1).

Our results have implications for Covid-19 infection prevention and control. In healthcare settings with estimated low values of pre-pandemic $\mathrm{R}_{0}^{\mathrm{H}}$, it is expected that classical barrier measuresreducing $p$, the probability of transmission per minute of contact - will suffice to prevent the spread of the virus. On the contrary, in healthcare settings where the estimated pre-pandemic $\mathrm{R}_{0}^{\mathrm{H}}$ is high, it is critical to implement additional control measures. These measures could include reducing the frequency $\left(n_{C t c}^{H}\right)$ and duration $\left(d_{c t c}^{H}\right)$ of contacts (e.g. through limiting patient-patient contacts by cancelling social activities and gatherings), limiting patient transfers, or reorganizing human resources and provisioning of care within the institution.

It should be underlined that this work's aim is to present a conceptual discussion about $R_{0}$ in healthcare settings. Hence, the elements presented here, and in particular the numerical estimates, should be interpreted in light of the following over-simplifications.

First, Covid-19 infection was simplified by assuming the same duration of infectivity, irrespective of the setting. However, in the community, individuals presenting symptoms may isolate themselves 
and stay at home whereas patients of healthcare settings will stay hospitalized. Considering such differences would lead to higher estimates of $\mathrm{R}_{0}^{\mathrm{H}}$.

Second, we assumed the same per-minute probability of transmission, irrespective of the setting and nature of contacts. However, some hospital contacts, such as those involving close proximity or invasive procedures, may pose greater transmission risk than others. Also, a higher concentration of severe infections, which may shed more virus [17], and the presence of immunosuppressed individuals, may entail a higher transmission probability in hospitals, therefore increasing $\mathrm{R}_{0}^{\mathrm{H}}$.

Third, $\mathrm{R}_{0}^{\mathrm{H}}$ may differ according to individual characteristics, notably for patients vs. healthcare workers. In addition, some individuals may be super-contactors or super-shedders, with a greater probability of generating secondary cases if infected.

Last, our $\mathrm{R}_{0}$ formula assumes random homogenous mixing between individuals in the population. For hospital networks, which are highly clustered due to ward structure and occupational hierarchies, this formula could be refined. Computing $\mathrm{R}_{0}^{\mathrm{H}}$ values using contact information at the ward level should facilitate more accurate estimates. Additionally, our formula makes the assumption that transmission risk increases linearly with contact duration, which may not be correct, especially for very long contacts. For instance, censoring contacts longer than 1 hour in the data from the first example gives an average contact duration within the facility of $15 \mathrm{~min}$, leading to a lower estimated $\mathrm{R}_{0}^{\mathrm{H}}$ of 3.37 .

In conclusion, pandemic Covid-19 continues to overwhelm healthcare institutions with critically ill and highly infectious patients, and nosocomial outbreaks pose great risk to patients and healthcare workers alike. Understanding how transmission risk varies between community and healthcare settings, and within and between different healthcare institutions such as hospitals and long-term care facilities, is fundamental to better predict risks of nosocomial outbreaks and inform appropriate infection control measures. 


\section{FUNDING}

This work was funded in part by the French government through the National Research Agency projects SPHINX (\# 17-CE36-0008-01) and MOD-COV. DS is also supported by a Canadian Institutes for Health Research doctoral foreign study award (Funding Reference Number 164263).

\section{REFERENCES}

1. Anderson RM, Heesterbeek $\mathrm{H}$, Klinkenberg D, Hollingsworth TD. How will country-based mitigation measures influence the course of the COVID-19 epidemic? Lancet 2020; 395(10228): 931-4.

2. Flaxman S, Mishra S, Gandy A, et al. Report 13: Estimating the number of infections and the impact of non-pharmaceutical interventions on COVID-19 in 11 European countries, 2020.

3. Pan A, Liu L, Wang C, et al. Association of Public Health Interventions With the Epidemiology of the COVID-19 Outbreak in Wuhan, China. Jama 2020.

4. Kucharski AJ, Russell TW, Diamond C, et al. Early dynamics of transmission and control of COVID-19: a mathematical modelling study. Lancet Infect Dis 2020.

5. Li R, Pei S, Chen B, et al. Substantial undocumented infection facilitates the rapid dissemination of novel coronavirus (SARS-CoV2). Science 2020.

6. Sanche S, Lin YT, Xu C, Romero-Severson E, Hengartner N, Ke R. High Contagiousness and Rapid Spread of Severe Acute Respiratory Syndrome Coronavirus 2. Emerg Infect Dis 2020; 26(7)

7. Zhang S, Diao M, Yu W, Pei L, Lin Z, Chen D. Estimation of the reproductive number of novel coronavirus (COVID-19) and the probable outbreak size on the Diamond Princess cruise ship: A data-driven analysis. Int J Infect Dis 2020; 93: 201-4. 
8. Wang D, Hu B, Hu C, et al. Clinical Characteristics of 138 Hospitalized Patients With 2019 Novel Coronavirus-Infected Pneumonia in Wuhan, China. Jama 2020.

9. Hsieh YH. 2015 Middle East Respiratory Syndrome Coronavirus (MERS-CoV) nosocomial outbreak in South Korea: insights from modeling. PeerJ 2015; 3: e1505.

10. Wölfel R, Corman VM, Guggemos W, et al. Virological assessment of hospitalized patients with COVID-2019. Nature 2020.

11. Béraud G, Kazmercziak S, Beutels P, et al. The French Connection: The First Large PopulationBased Contact Survey in France Relevant for the Spread of Infectious Diseases. PLoS One 2015; 10(7): e0133203.

12. Alizon $S$, Bénéteau $T$, Choisy $M$, et al. Estimating the basic reproduction number of the COVID-19 epidemic in France, 2020.

13. Di Domenico L, Pullano G, Sabbatini C, Boëlle P-Y, Colizza V. Expected impact of lockdown in île-de-France and possible exit strategies, 2020.

14. Duval A, Obadia T, Martinet $\mathrm{L}$, et al. Measuring dynamic social contacts in a rehabilitation hospital: effect of wards, patient and staff characteristics. Sci Rep 2018; 8(1): 1686.

15. Voirin N, Payet C, Barrat A, et al. Combining high-resolution contact data with virological data to investigate influenza transmission in a tertiary care hospital. Infect Control Hosp Epidemiol 2015; 36(3): 254-60.

16. Assab R, Temime $\mathrm{L}$. The role of hand hygiene in controlling norovirus spread in nursing homes. BMC Infect Dis 2016; 16: 395.

17. Xu K, Chen Y, Yuan J, et al. Factors associated with prolonged viral RNA shedding in patients with COVID-19. Clin Infect Dis 2020. 
medRxiv preprint doi: https://doi.org/10.1101/2020.04.20.20072462; this version posted April 24, 2020. The copyright holder for this preprint (which was not certified by peer review) is the author/funder, who has granted medRxiv a license to display the preprint in perpetuity. All rights reserved. No reuse allowed without permission.

Table 1 - Range of estimated reproduction numbers $\left(\mathrm{R}_{0}^{\mathrm{H}}\right)$ values obtained when $d_{c t c}^{H}$ ranges from 10 to 40 minutes, for different assumed values of $\mathrm{R}_{0}^{\mathrm{C}}$ (rows) and $n_{\text {Ctc }}^{H}$ (columns)

\begin{tabular}{|c|l|c|c|c|c|c|}
\cline { 2 - 7 } \multicolumn{2}{c|}{} & \multicolumn{5}{c|}{ Average number of daily contacts in the healthcare setting $\left(n_{\text {Ctc }}^{\mathrm{N}}\right.$ ) } \\
\cline { 2 - 7 } \multicolumn{2}{c|}{} & 5 & 10 & 15 & 18 & 20 \\
\hline \multirow{3}{*}{$\begin{array}{c}\text { Assumed value for } \\
\text { basic reproduction }\end{array}$} & 2 & $0.4-1.7$ & $0.8-3.3$ & $1.3-5$ & $1.5-6$ & $1.7-6.7$ \\
\cline { 2 - 7 } number in the & 2.5 & $0.5-2.1$ & $1-4.2$ & $1.6-6.3$ & $1.9-7.5$ & $2.1-8.3$ \\
\cline { 2 - 7 } & 3 & $0.6-2.5$ & $1.3-5$ & $1.9-7.5$ & $2.3-9$ & $2.5-10$ \\
\cline { 2 - 7 } community $\left(\mathrm{R}_{0}^{\mathrm{C}}\right)$ & 3.5 & $0.7-2.9$ & $1.5-5.8$ & $2.2-8.8$ & $2.6-10.5$ & $2.9-11.7$ \\
\cline { 2 - 7 } & 4 & $0.8-3.3$ & $1.7-6.7$ & $2.5-10$ & $3-12$ & $3.3-13.3$ \\
\hline
\end{tabular}

